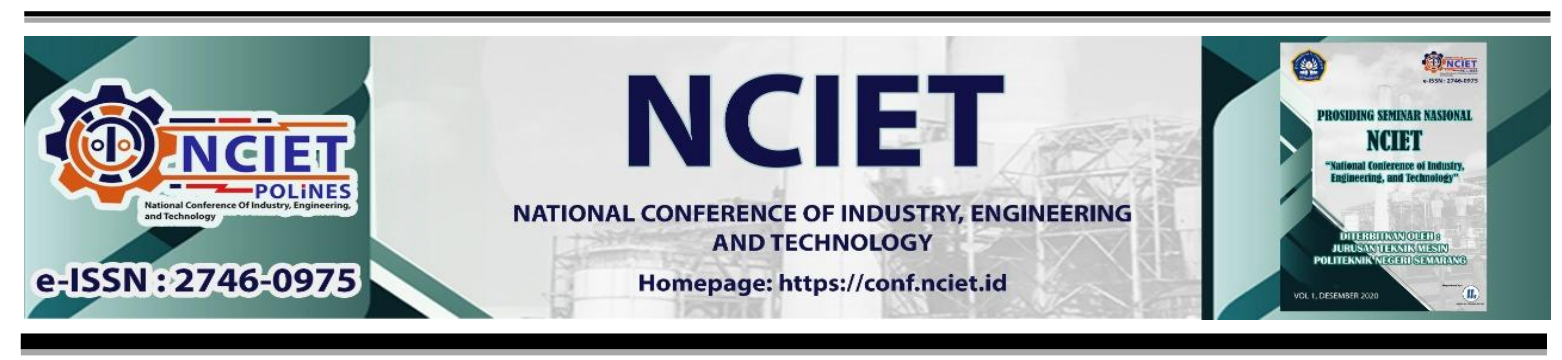

Prosiding Seminar Nasional NCIET Vol.1 (2020) B293-B300

$1^{\text {st }}$ National Conference of Industry, Engineering and Technology 2020,

Semarang, Indonesia.

\title{
PERFORMANCE ORGANIC RANKINE CYCLE SYSTEM (ORCS) DENGAN FLUIDA KERJA HCFC123 MENGGUNAKAN TEMPERATURE GAS BUANG YANG RENDAH
}

\author{
Mochamad Denny Surindra* \\ Jurusan Teknik Mesin, Politeknik Negeri Semarang \\ Jl. Prof. H. Soedarto S.H., Tembalang, Semarang, 50275 \\ *E-mail: dennysurindra@polines.ac.id
}

\begin{abstract}
Abstrak
Aplikasi ORC system dengan menggunakan fluida kerja HCFC123 dimana memanfaatkan panas yang terbuang, mesin diesel, panas matahari, panas bumi menjadikan sumber energi terbarukan. Evaporator menghasilkan heat input terbesar $50,58 \mathrm{~kJ} / \mathrm{s}$, sedangkan kondensor heat output sebesar 42, $31 \mathrm{~kJ} / \mathrm{s}$. Pump work input terbesar $0,23 \mathrm{~kJ} / \mathrm{s}$ pada laju aliran massa 0,175 $\mathrm{kg} / \mathrm{s}$, sedangkan scroll expander work output $6,5 \mathrm{~kJ} / \mathrm{s}$ pada laju aliran massa $0,2 \mathrm{~kg} / \mathrm{s}$. Hal ini menunjukan bahwa ORC system menghasilkan energy yang jauh lebih besar dibandingkan energy yang dibutuhkan untuk menggerakan pompa dengan thermal efficiency terbesar adalah $12 \%$ pada laju aliran masa $0,2 \mathrm{~kg} / \mathrm{s}$.
\end{abstract}

Kata Kunci: Organic Rankine Cycle System; ORCS, HCFC123; Fluida Kerja

\section{PENDAHULUAN}

Produksi energi fosil terutama minyak mentah dan komitmen global dalam mengurangi emisi gas rumah kaca telah mendorong pemerintah untuk meningkatkan peran energi baru dan terbarukan secara terus menerus untuk menjaga ketahanan dan kemerdekaan energi. Sebagaimana tertuang dalam Peraturan Pemerintah Nomor 79 Tahun 2014 tentang kebijakan energi nasional, target bauran energi baru dan terbarukan minimal $23 \%$ pada tahun 2025 dan $31 \%$ pada tahun 2050 . Indonesia memiliki potensi energi baru dan terbarukan yang cukup membanggakan memenuhi target bauran energi primer seperti terlihat pada Tabel 1 di bawah ini. 
Tabel 1. Potensial Energi baru dan terbarukan

\begin{tabular}{ll}
\hline \multicolumn{1}{c}{ ENERGY SOURCE } & \multicolumn{1}{c}{ POTENTIALLY } \\
\hline Hydro & $94.3 \mathrm{GW}$ \\
Geothermal & $28.5 \mathrm{GW}$ \\
Bioenergy & Bio PP $32.6 \mathrm{GW}$ \\
Solar Energy & Bio fuel : 200 Thousand bpd \\
Wind & $207.8 \mathrm{GWp}$ \\
Ocean Energy & $60.6 \mathrm{GW}$ \\
\hline
\end{tabular}

Sumber: Indonesia Energy Outlook 2019, Tahun 2019

Total potensi energi terbarukan tersebut setara dengan $442 \mathrm{GW}$ untuk pembangkit listrik, sedangkan 200 ribu bpd (barrel per hari) biofuel dan biogas digunakan sebagai bahan bakar transportasi, rumah tangga, sektor komersial dan industry. NRE untuk pembangkit listrik pada tahun 2018 sebesar 8,8 GW atau 14\% dari total kapasitas pembangkit 64,5 GW (fosil dan non-fosil). Rendahnya pemanfaatan EBT untuk pembangkit listrik disebabkan oleh tingginya biaya produksi pembangkit EBT sehingga sulit bersaing dengan pembangkit berbahan bakar fosil. Selain itu, kurangnya dukungan industri dalam negeri terkait komponen pembangkit energi terbarukan dan sulitnya memperoleh pembiayaan dengan bunga rendah menjadi penyebab lambatnya pengembangan energi terbarukan [1].

Aplikasi ORC system lebih kompak daripada dari pada turbin uap karena densitas fluida kerja organik lebih tinggi daripada pembangkit listrik tenaga uap. Beberapa eksperimental dilakukan seperti yang dialkukan oleh Surindra [2] dengan tujuan meningkatkan kinerja ekspander dan efisiensi siklus. Li et al. [3] menyelidiki efek laju aliran massa fluida kerja pada kinerja ORC, dengan menggunakan pemanas listrik sebagai sumber panas, R123 menjadi fluida kerja, dan turbin aliran aksial satu tahap menjadi expander. Ketika temperature masuk ke evaporator konstan, tekanan masuk turbin dan kecepatan putar meningkat seiring dengan laju aliran massa [4]. Yamamoto et al.. [5] membangun sistem ORC terintegrasi dengan turbin aliran radial untuk menyelidiki kinerja turbin dengan R123 sebagai fluida kerja. Daya keluaran turbin pada awalnya meningkat dan kemudian menurun dengan kecepatan rotasinya, oleh karena itu daya listrik maksimum sistem ada pada kecepatan putar yang dioptimalkan. Prasetyo et al [6] juga menggunakan R123 untuk menguji performance system yang ditijau dari perubahan temperature superheat.

Sangat menarik ORC system dikaji lebih lanjut karena hanya membutuhkan sumber panas yang cukup rendah untuk mengoperasikan sistemnya. Dalam paper ini mengungkap 
performance HCFC123 di operasional ORC system dengan menggunakan sumber panas di evaporator sebesar $120^{\circ} \mathrm{C}$.

\section{METODE PENELITIAN}

Pompa memasok fluida kerja yang berada pada fase cair ke evaporator, dimana fluida kerja dipanaskan dan diuapkan oleh oli pelumas yang dipanaskan dan difungdikan sebagai sumber panas. Uap tekanan tinggi mengalir ke expander dan energy uap superheat diekspansikan menjadi energy kinetic. Uap tekanan rendah keluar expander dan dialirkan ke kondensor untuk merubah menjadi fase cair dengan memanfaatkan air dingin dari chiller. Cairan tersedia di outlet kondensor, dan kemudian dipompa kembali ke evaporator dan siklus baru dimulai.

Daya poros pompa dapat dihitung dengan tekanan dan temperature yang diukur, sementara konsumsi daya diukur dengan konverter frekuensi pompa. Daya poros pompa (Wp,pump) dapat diekpresikan dengan persamaan sebagai berikut:

$$
W_{p}=\dot{m}\left(h_{3}-h_{2}\right)
$$

Uap yang mengalami kompresi mengalir melalui evaporator dan keluar pada kondisi superheat. Selama proses infiltrasi panas dari sisi inlet ke sisi outlet, oli yang panas menginfiltrasi dan memberikan energi panas ke dalam fluida kerja. Total laju perpindahan panas (Qevap) dari sumber panas ke fluida kerja dalam evaporator ditunjukkan dalam persamaan sebagai berikut:

$$
Q_{\text {evap }}=\dot{m}\left(h_{3}-h_{2}\right)
$$

Uap superheat pada sisi keluar evaporator mengalir ke scroll expander dimana uap superheat tersebut berekspansi memberikan energy dan menghasilkan daya keluaran dengan memutar poros. Tekanan dan penurunan suhu selama proses ini kemudian dilepaskan ke sisi keluar scroll expander. Dengan mengabaikan aliran perpindahan panas masuk dan mengalir keluar ke sekitarnya, daya output scroll expander (Wt) dapat ditulis sebagai:

$$
W_{\text {turbine }}=\dot{m}\left(h_{3}-h_{4}\right)
$$


Kondensor memfasilitasi perpindahan panas dari uap ke air pendingin yang mengalir dalam saluran terpisah. Menurut prinsip keseimbangan massa dan energi untuk volume yang dikendalikan pada kondensor, panas keluaran dapat ditulis sebagai berikut ini:

$$
Q_{\text {cond }}=\dot{m}\left(h_{1}-h_{4}\right)
$$

Efisiensi termal dapat direpresentasikan sebagai rasio antara output total terhadap daya input dan laju transfer panas. Efisiensi termal dapat digambarkan sebagai berikut ini:

$$
\begin{gathered}
\eta=\frac{W_{\text {turb }} /_{\dot{m}}-W_{\text {pump }} /_{\dot{m}}}{Q_{\text {in }} / \dot{m}} \\
\eta=\frac{\left(h_{3}-h_{4}\right)-\left(h_{2}-h_{1}\right)}{h_{3}-h_{2}}
\end{gathered}
$$

Karena energi input dan work output sama dengan total energi panas yang beroperasi, maka efisiensi termal dapat juga diekspresikan sebagai berikut ini:

$$
\begin{gathered}
\eta=\frac{Q_{\text {in } / \dot{m}}-Q_{\text {out } / \dot{m}}}{Q_{\text {in }} / \dot{m}} \\
\eta=1-\frac{Q_{\text {out } / \dot{m}}}{Q_{\text {in } / \dot{m}}} \\
\eta=1-\frac{\left(h_{4}-h_{1}\right)}{h_{3}-h_{2}}
\end{gathered}
$$

\section{HASIL DAN PEMBAHASAN}

Dengan mensimulasikan panas buang sebesar 1200C masuk ke dalam evaporator Thin yang memanfaatkan oli pelumas yang dipanaskan dengan heater, ORC system dievalusi kinerjanya menggunakan fluida kerja $\mathrm{HCFC} 123$. Laju aliran massa fluida kerja diatur modulasinya sehingga kecepatan fluida kerja dapat bervarisi yaitu $0,1 \mathrm{~kg} / \mathrm{s}, 0,12 \mathrm{~kg} / \mathrm{s}, 0,15$ $\mathrm{kg} / \mathrm{s}, 0,175 \mathrm{~kg} / \mathrm{s}$ dan $0,2 \mathrm{~kg} / \mathrm{s}$. Kondisi steady state termodinamika yang terdiri dari 
temperature dan tekanan, akan dipertahankan selama 20 menit untuk mengambil data setiap komponen yaitu pompa, evaporator, scroll expander dan kondensor.

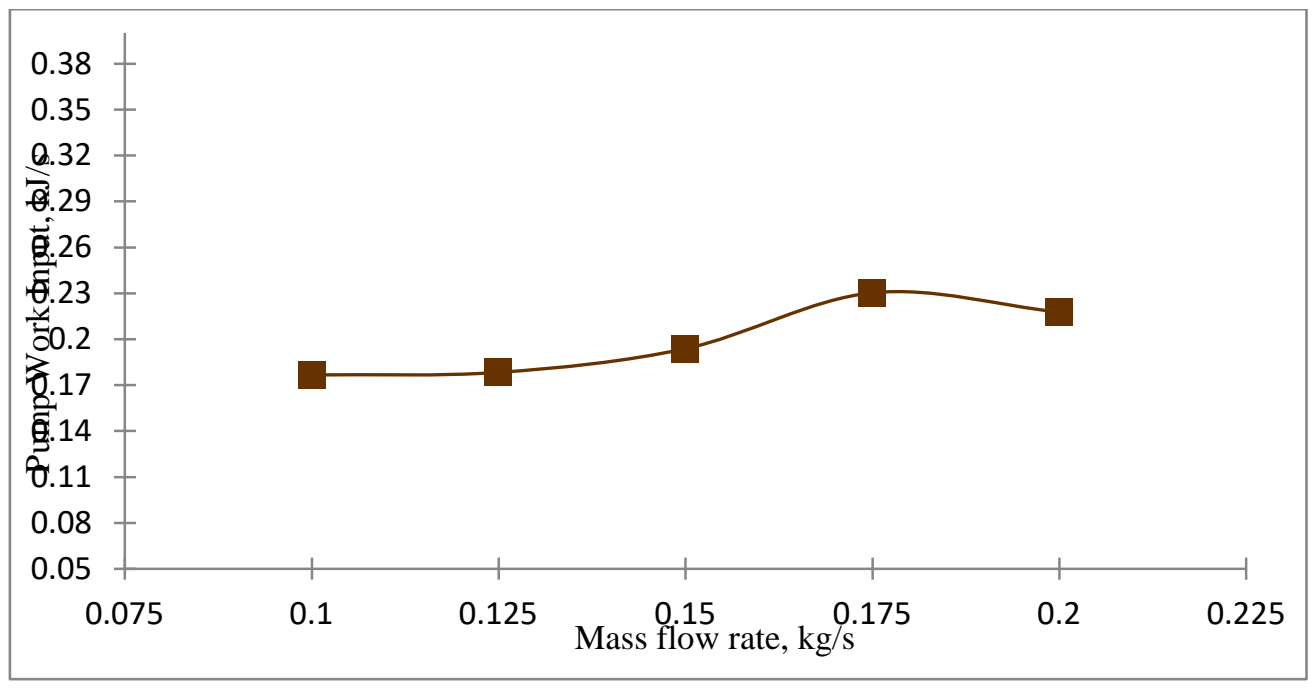

Gambar 2. Perubahan laju aliran massa terhadap pump work input

Pump work input mengalami peningkatan yang tidak significant meskipun laju aliran masa divariasikan dari $0,1 \mathrm{~kg} / \mathrm{s}$ sampai $0,2 \mathrm{~kg} / \mathrm{s}$. Tercatat pump work input yang paling tinggi sebesar $0,23 \mathrm{~kJ} / \mathrm{s}$ saat mass flow rate $0.175 \mathrm{~kg} / \mathrm{s}$, seperti yang terlihat didalam Gambar 2. Perubahan laju aliran masa dilakukan dengan cara mengatur frekuensi kecepatan putar pompa refrigerant. Semakin besar frekuensi pompa semakin besar kecepatan pompa dan menghasilkan laju aliran massa semakin besar. Pada saat laju aliran massa fuida kerja HCFC123 0,1 kg/s menghasilkan pump work input sebesar 0,18 kJ/s, sedangkan pada saat laju aliran massa disetting $0,2 \mathrm{~kg} / \mathrm{s}$ menghasilkan pump work input sebesar $0,22 \mathrm{~kJ} / \mathrm{s}$.

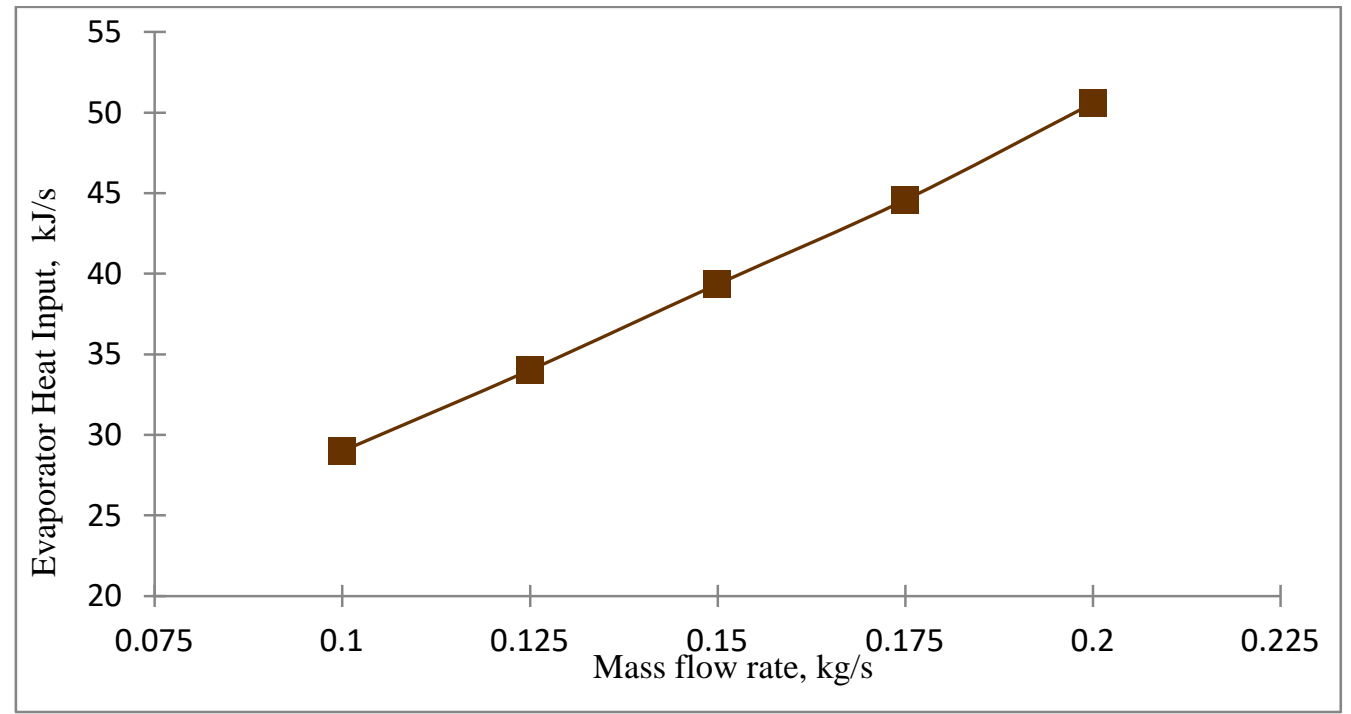

Gambar 3. Perubahan laju aliran massa terhadap Evaporator Heat Input 
Perubahan laju aliran massa mempengaruhi perubahan evaporator heat input yang sangat significant seperti yang terlihat dalam gambar 3. Evaporator sebagai tempat perpindahan panas mendapatkan sumber panas masuk Thin ditetapkan sebesar $120^{\circ} \mathrm{C}$ dar pelumas oli karena mempunyai perubahan temperature yang minim sedangkan refrigerant mengalir di TC in dan keluar TC out diamati perubahan temperaturenya. Pada saat laju aliran massa 0,1 kg/s Evaporator Heat Input sebesar $29 \mathrm{~kJ} / \mathrm{s}$ dan kemudian berturut-turut sesuai dengan bertambahnya laju aliran massa didapatkan $34 \mathrm{~kJ} / \mathrm{s}, 39,35 \mathrm{~kJ} / \mathrm{s}, 44,58 \mathrm{~kJ} / \mathrm{s}$ dan $50,58 \mathrm{~kJ} / \mathrm{s}$.

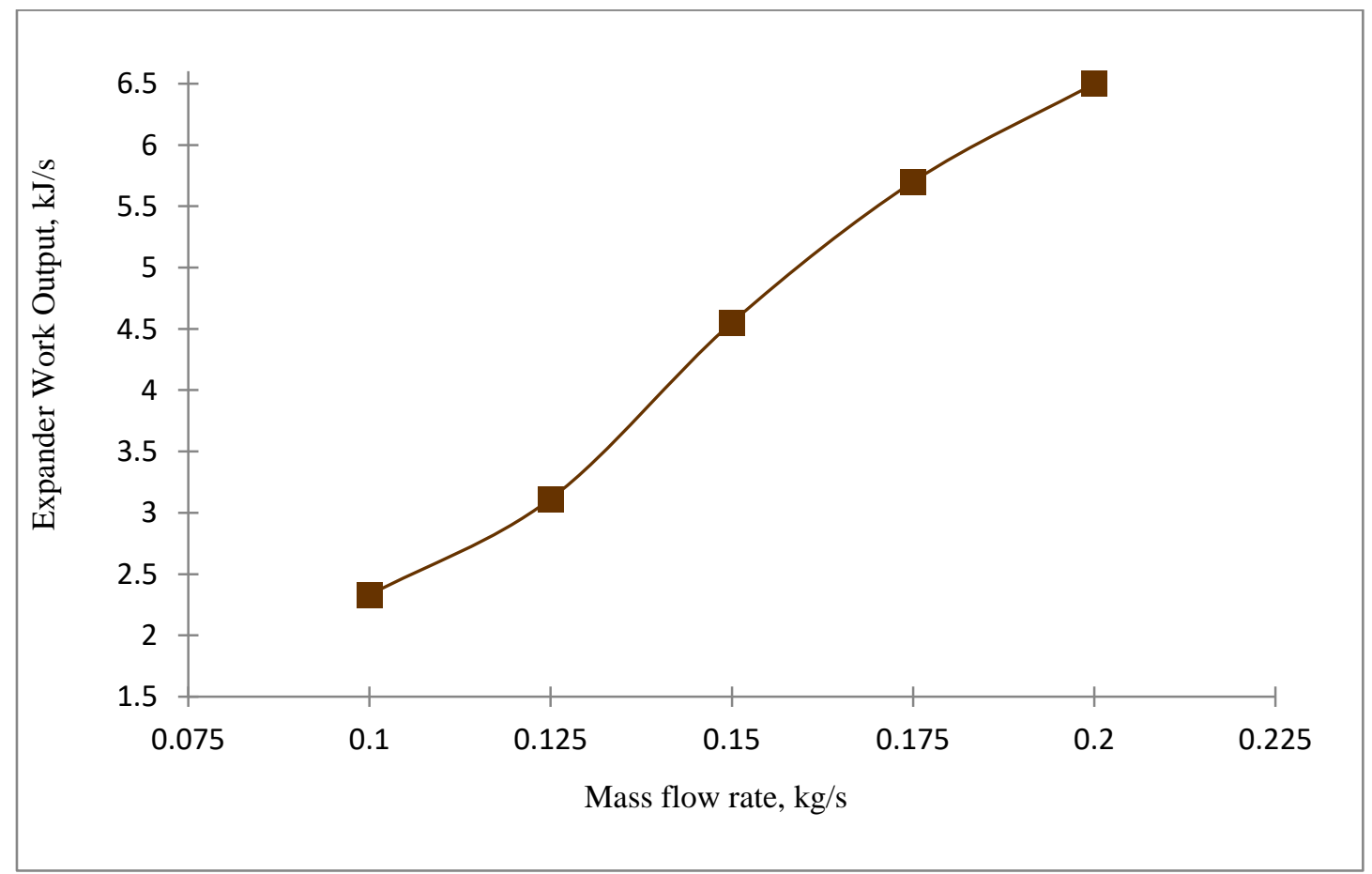

Gambar 4. Perubahan laju aliran massa terhadap daya output Scroll expander

Expansi proses memanfaatkan scroll yang diambil dari compressor cool storage. Scroll ini dimanfaatkan utk melakukan expansi sehingga disebut scroll expander. Laju aliran massa yang divariasikan $0,1 \mathrm{~kg} / \mathrm{s}$ sampai $0,2 \mathrm{~kg} / \mathrm{s}$ melaju dari keluar dari evaporator dengan sejumlah energy dan menabrak scroll yang mengakibatkan scroll tersebut berputar sehingga energy dari fluida kerja diserap oleh scroll expander yang dihubungkan dengan besi pejal dan generator sehingga generator berputar dan menghasilkan listrik. Pada saat laju aliran massa $0,1 \mathrm{~kg} / \mathrm{s}$, scroll expander menghasilkan 2,34 kJ/s kemudian dengan bertambahnya laju aliran massa berturut-turut $3,1 \mathrm{~kJ} / \mathrm{s}, 4,55 \mathrm{~kJ} / \mathrm{s}$, dan $5,7 \mathrm{~kJ} / \mathrm{s}$ seperti yang terlihat dalam Gambar 4. Ketika laju aliran massa terbesar yaitu 0,2 kJ/s sroll expander menghasilkan energy scroll expander work output sebesar $6,5 \mathrm{~kJ} / \mathrm{s}$. 


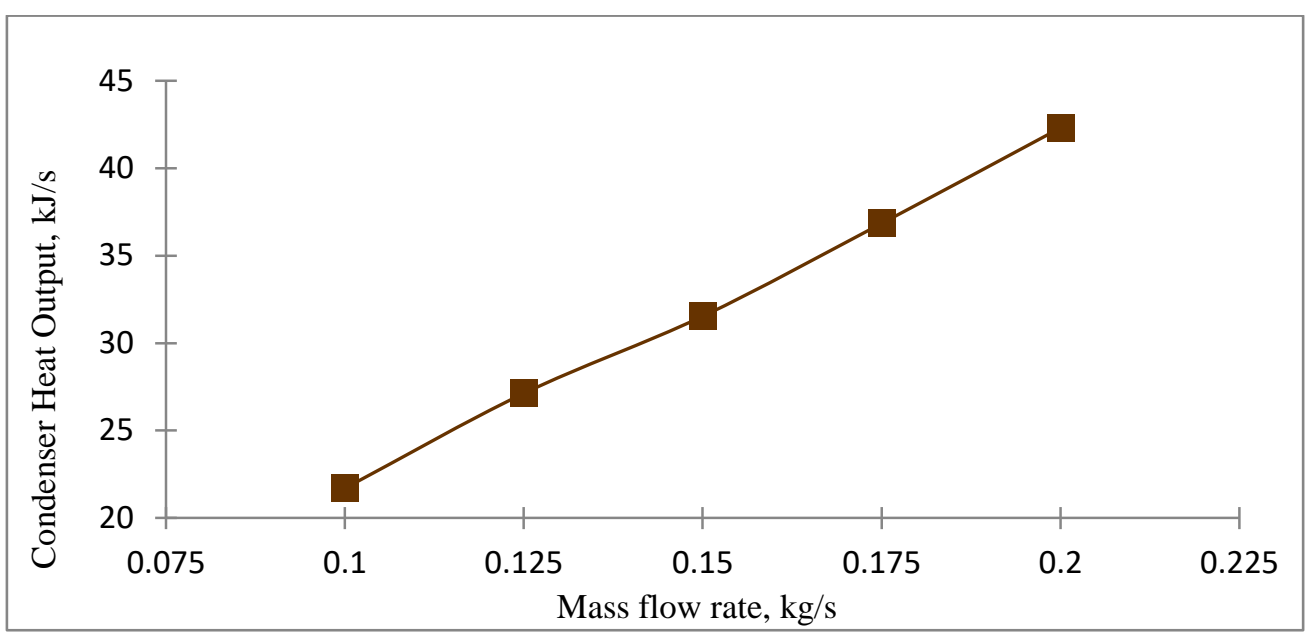

Gambar 5. Perubahan laju aliran masa terhadap Laju perpindahan panas Kondensor

Fluida kerja HCFC123 keluar dari scroll expander akan memasuki condenser untuk melakukan proses kondensasi. Condesor menggunakan plate heat exchanger (PHE) dengan menggunakan air pendingin cooling tower, sehingga temperature cooling tower sangat dipengaruhi oleh temperature lingkungan. Temperature air pendingin berkisar anatar $26^{\circ} \mathrm{C}$ sampai dengan temperature $28^{\circ} \mathrm{C}$. Gambar 5 memperlihatkan bahwa dengan bertambahnya laju aliran massa fluida kerja maka akan bertambah pula condenser heat output. Pada saat laju aliran massa fluida kerja sebesar $0,1 \mathrm{~kg} / \mathrm{s}$, besarnya kondensor heat output adalah 21,69 kJ/s, sedangkan pada saat laju aliran massa fluida kerja sebesar 0,2 kg/s didapatkan dari hasil perhitungan besarnya condenser heat output sebesar $42,31 \mathrm{~kJ} / \mathrm{s}$.

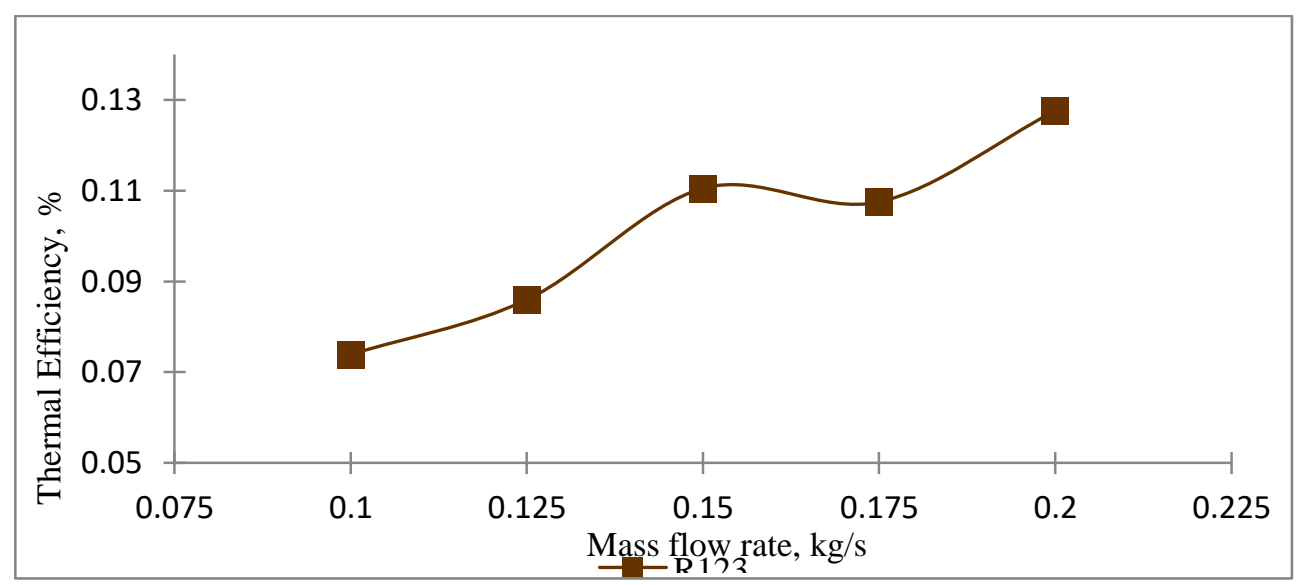

Gambar 6. Perubahan laju aliran massa terhadap Effisiensi thermal

Gambar 6 memperlihatkan kinerja ORC system yang telang dirangkai menjadi system pembangkit energy dengan hasil anatara 7,3\%,8,5\%,11\%, 10\% dan 12\%, dengan laju aliran massa $0,1 \mathrm{~kg} / \mathrm{s}$ sampai dengan $02 \mathrm{~kg} / \mathrm{s}$. Peningkatan thermal efficiency terjadi sangat significant dari laju aliran massa $0,1 \mathrm{~kg} / \mathrm{s}$ sampai dengan $0,15 \mathrm{~kg} / \mathrm{s}$ dimana thermal efficiency mencapai $11 \%$, tetapi pada saat laju aliran massa $0,175 \mathrm{~kg} / \mathrm{s}$ terjadi penurunan 
Thermal effisiensi sebesar 10\%. Kesemuanya hasil pengujian ORC system tertinggi tercatat $12 \%$ pada laju aliran massa fluida kerja $0,2 \mathrm{~kg} / \mathrm{s}$.

\section{KESIMPULAN}

Fluida kerja HCFC123 telah digunakan dalam penelitian ORC system yang mengasumsikan waste heat dengan oli pelumas yang dipanaskan dengan heater. Fluida kerja HCFC123 ini dipompakan keseluruh system dengan menggunakan pompa torak dan menghasilkan kinerja ORC system sehingga dapat diambil kesimpulan sebagai berikut:

1. HCFC123 dapat diaplikasikan ke dalam system ORC dengan laju aliran massa minimum sebesar $0,1 \mathrm{~kg} / \mathrm{s}$ dan maksimum $0,2 \mathrm{~kg} / \mathrm{s}$.

2. Perpindahan energy panas di evaporator yaitu evaporator heat input terbesar adalah $50,58 \mathrm{~kJ} / \mathrm{s}$, sedangkan kondensor heat output sebesar $42,31 \mathrm{~kJ} / \mathrm{s}$.

3. Pump work input terbesar sebesar $0,23 \mathrm{~kJ} / \mathrm{s}$ pada saat laju aliran massa sebesar $0,175 \mathrm{~kg} / \mathrm{s}$, sedangkan scroll expander work output terbesar $6,5 \mathrm{~kJ} / \mathrm{s}$ pada laju aliran massa $0,2 \mathrm{~kg} / \mathrm{s}$. Hal ini menunjukan bahwa ORC system menghasilkan energy yang jauh lebih besar dibandingkan energy yang dibutuhkan untuk menggerakan pompa.

4. Thermal efficiency yang dihasilkan terbesar adalah $12 \%$ pada saat laju aliran masa $0,2 \mathrm{~kg} / \mathrm{s}$.

\section{DAFTAR PUSTAKA}

[1].National Energy Council, 2019).

[2].Surindra, MD, Eksperimental Studi Performance Organic Rankine Cycle (ORC) Mneggunakan Fluida Kerja R245fa dengan Sumber Panas di Evaporator $120^{\circ} \mathrm{C}$. Jurnal Rekayasa Mesin 2019, Desember Vol.14,No.3 hal. 135-141

[3].M.Q. Li, J.F. Wang, W.F. He, L. Gao, B. Wang, S.L. Ma, Y.P. Dai, Construction and preliminary test of a low-temperature regenerative organic Rankine cycle (ORC) using R123, J. Renew. Energy 57 (2013) 216-222.

[4].Surindra, M.D.; Caesarendra, W.; Prasetyo, T.; Mahlia, T.M.I.; Taufik, T. Comparison of the Utilization of $110^{\circ} \mathrm{C}$ and $120^{\circ} \mathrm{C}$ Heat Sources in a Geothermal Energy System Using Organic Rankine Cycle (ORC) with R245fa, R123, and Mixed-Ratio Fluids as Working Fluids. Processes 2019, 7, 113.

[5].T. Yamamoto, T. Furuhata, N. Arai, K. Mori, Design and testing of the organic Rankine cycle, J. Energy. 26 (2001) 239-251.

[6].Prasetyo, T.; Surindra, M.D.; Caesarendra, W.; Taufik, T. Glowacz A., Irfan M., Glowacz. W., Influence of Superheated Vapour in Organic Rankine Cycles with Working Fluid R123 Utilizing Low-Temperature Geothermal Resources. Symmetry 2020, 12(9), 1463. 